\title{
Colonisation of pregnant and puerperal women and neonates with Chlamydia trachomatis
}

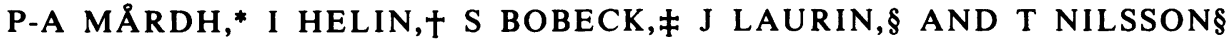 \\ From the *Institute of Medical Microbiology, University of Lund; the Departments of + Paediatrics and \\ $¥$ Gynaecology, Landskrona Hospital; and the §Department of Obstetrics and Gynaecology, Helsingborg \\ Hospital, Sweden
}

SUMMARY Chlamydia trachomatis was cultured from cervical specimens of $14(16 \cdot 1 \%)$ of 231 women applying for legal abortion and from $23(8 \cdot 7 \%)$ of 273 puerperal women. The chlamydial isolation rate was related to the women's age. Of the pregnant and puerperal women under 20 years $C$ trachomatis was isolated in $10 \%$ and $24 \%$ respectively; in those aged between 20 and 24 years the rates were $8 \cdot 7 \%$ and $10 \cdot 2 \%$ respectively whereas in those over 24 years the rates were $4 \cdot 2 \%$ in both groups. Chlamydia were isolated more frequently from cervical specimens than from urethral specimens. However, if a cervical specimen alone had been examined the diagnosis would have been missed in three $(17 \%)$ of 18 women.

IgG antichlamydial antibodies (titre $>1 / 32$ ) were detected by a micro-immunofluorescence test in samples of cord blood from $35(25 \%)$ of 139 infants of the puerperal women. Of the 23 infants born to mothers harbouring chlamydia in the cervix $C$ trachomatis was isolated from the conjuntival folds in five $(22 \cdot 5 \%)$. The chlamydial isolation rate from the eyes of the neonates was related to the time of sampling. None of the 108 infants examined between 6 and 7 days old was chlamydia-positive whereas chlamydia could be recovered from the conjunctival folds of four of them when re-examined from three to 23 days later.

\section{Introduction}

Chlamydia trachomatis is one of the most common pathogens recovered from the genital tract. The organism is generally transmitted by sexual intercourse. ${ }^{1}$ It is a frequent cause of serious complications following primary genital infections both in women (namely, acute salpingitis ${ }^{2}$ ) and in men (namely, acute epididymitis ${ }^{3}$ ). Asymptomatic female carriers of $C$ trachomatis occur at least as frequently as those of Neisseria gonorrhoeae. ${ }^{4} 5$ However signs of inflammation are generally present in women with genital chlamydial infection. ${ }^{6}$

Chlamydia may be transmitted from mother to infant at delivery. $C$ trachomatis has been isolated from the eyes, the nasopharynx, the larynx, the lungs, the vagina, and from faecal specimens of infants born to mothers harbouring the organism in the cervix. ${ }^{7}$ Such infection of the infant may result in conjunctivitis, ${ }^{89}$ which generally runs a mild clinical

Address for reprints: Dr P-A Mårdh, Institute of Medical Microbiology, Sölvegatan 23, S-223 62 Lund, Sweden

Received for publication 3 September 1979 course. However severe exudative ophthalmitis may occur, ${ }^{10}$ and rarely conjunctival scarring and pannus develop as sequelae. ${ }^{11-13}$ In recent years, $C$ trachomatis has also been established as one of the most common causes of neonatal pneumonia. ${ }^{14} 15$ Neonates may also harbour this organism without showing signs of infection. ${ }^{15}$

The present study was performed to: (a) study the incidence of infections with $C$ trachomatis and $N$ gonorrhoeae in different age groups of pregnant (women applying for legal abortion) and puerperal women; (b) determine the presence of IgG antichlamydial antibodies in cord blood of infants of the mothers studied; and (c) investigate chlamydial colonisation in the eyes of infants born to mothers infected with the organism.

\section{Patients and methods}

STUDY POPULATION AND SAMPLING Group 1

Two hundred and thirty-five women applying for legal abortion (group 1) in the cities of Landskrona and Helsingborg between the eighth and thirteenth week of pregnancy were examined for cervical 
infection with $C$ trachomatis; specimens for culture for $N$ gonorrhoeae were collected from the urethra, the cervix, and the rectum. All the 235 women studied had abortions performed.

\section{Group 2}

Cervical cultures for $C$ trachomatis were also obtained from 293 puerperal women (group 2) from the city of Landskrona; samples were taken on the sixth or seventh day after delivery. Specimens for chlamydial isolation were also collected from the urethra in 169 of these women. Specimens for isolation of $N$ gonorrhoeae were collected from the urethra, the cervix, and the rectum in 185 women in this group.

\section{Group 3}

Specimens were collected from the conjunctival folds of the infants born to the first 108 puerperal women studied (group 3) at six or seven days after birth. Of the remaining 185 puerperal women, conjunctival specimens were collected only from those neonates whose mothers had been found to be infected with chlamydia; samples were collected from these infants between 10 and 30 days after birth.

\section{CULTURE TECHNIQUES}

Specimens for chlamydial isolation were collected with a calcium-alginate swab (Inolex Corp, Glenwood, Illinois) by gentle rotation before withdrawal of the swab from the sampling site. The swabs were transported in a sucrose-phosphate buffer (2-SP), ${ }^{16}$ containing $5 \%$ fetal calf serum, $10 \mu \mathrm{g}$ gentamycin, $100 \mu \mathrm{g}$ vancomycin, and $2.5 \mu \mathrm{g}$ amphotericin B per $\mathrm{ml}$. Specimens were transported chilled $\left(14^{\circ} \mathrm{C}\right)$ to the laboratory, where approximately $95 \%$ of them were stored at $4^{\circ} \mathrm{C}$ for less than 48 hours before inoculation on to tissue cultures. The remaining $5 \%$ of specimens had been stored at $-20^{\circ} \mathrm{C}$ before being tested. Chlamydial isolation was made on cycloheximide-treated McCoy cells according to a technique described by Ripa and Mårdh, ${ }^{17}$ although RPMI 1640 was used as tissue culture medium.

The sampling technique and the methods used for the isolation and identification of $N$ gonorrhoeae were those described elsewhere. ${ }^{18}$

\section{SEROLOGICAL TESTS}

Specimens of cord blood from 139 of the neonates were tested for IgG antichlamydial antibodies with a modified micro-immunofluorescence (micro-IF) test using pools of antigens as described by Treharne and co-workers. ${ }^{19}$

\section{TREATMENT}

Women in group 1 found to be infected with chlamydia were given doxycycline $200 \mathrm{mg}$ (Vibramycin, Pfizer) daily for five days followed by $100 \mathrm{mg}$ daily for 10 days; their sexual consorts received the same treatment. Women in group 2 infected with the organism received doxycycline $100 \mathrm{mg}$ daily for 14 days; the same treatment was prescribed for their husbands. Infants with positive chlamydial isolation from the eyes were given erythromycin $20-25 \mathrm{mg} / \mathrm{kg}$ body weight (Abboticin, Abbott) twice daily for 10 days and chloromycetin ointment (Chloromycetin, Parke-Davis) locally.

\section{Results}

\section{CULTURAL STUDIES}

\section{Group I}

In four $(1 \cdot 7 \%)$ of the 236 women in group 1 the cervical culture results were inconclusive owing to a non-specific cytopathogenic effect. $C$ trachomatis was isolated from $14(6 \cdot 2 \%)$ of the remaining 231 women (Table I). Women of less than 20 years had the highest rate of positive culture results $(10 \%)$ (Table I).

$N$ gonorrhoeae was recovered from two $(0.9 \%)$ women in group 1, one of whom also harboured chlamydia.

\section{Group 2}

Chlamydial cultures from $20(6 \cdot 8 \%)$ of the 293 women in this group gave an inconclusive result. $C$ trachomatis was isolated from $23(8 \cdot 4 \%)$ of the remaining 273 women. Also in this group the isolation rate was related to age (Table I). Of the women under 20 years $24 \%$ harboured the organism compared with $4 \cdot 4 \%$ of those of 25 years or older.

$N$ gonorrhoeae was not isolated from any of the 185 puerperal women.

TABLE I Isolation of Chlamydia trachomatis from the cervix in different age groups of 231 pregnant (group 1) and 273 puerperal (group 2) women

\begin{tabular}{llccc}
\hline & \multicolumn{2}{l}{$\begin{array}{l}\text { Positive chlamydial isolation (out of total in each } \\
\text { age range) }\end{array}$} \\
\cline { 2 - 5 } $\begin{array}{l}\text { Age } \\
\text { (yrs) }\end{array}$ & No & $\%$ & Group 2* & \\
\hline$\leqslant 19$ & $2 / 22$ & $10 \cdot 0$ & No & $\%$ \\
$20-24$ & $6 / 69$ & $8 \cdot 7$ & $6 / 25$ & $24 \cdot 0$ \\
$25-29$ & $3 / 49$ & $6 \cdot 0$ & $11 / 108$ & $10 \cdot 2$ \\
$\geqslant 30$ & $3 / 91$ & $3 \cdot 9$ & $3 / 87$ & $3 \cdot 4$ \\
Total & $14 / 231$ & $6 \cdot 1$ & $3 / 53$ & $5 \cdot 7$ \\
\hline
\end{tabular}

* The four women in group 1 and the 20 women in group 2 with inconclusive culture results have been excluded. 
Comparison of cervical and urethral cultures (group 2)

The culture results for the 169 puerperal women from whom specimens for chlamydial isolation were collected from both the cervix and the urethra are shown in Table II. Eighteen patients harboured chlamydia-in most instances in the cervix ( 15 cases), although specimens from the cervix most often caused a non-specific cytopathogenic effect in the tissue cultures.

TABLE II Comparison of chlamydial culture results in cervical and urethral specimens from 169 puerperal women (group 2)

\begin{tabular}{lll}
\hline Culture result* & & $\begin{array}{l}\text { No of positive } \\
\text { results } \\
\text { from both sites }\end{array}$ \\
\hline Cervix & Urethra & 134 \\
\hline+ & - & 11 \\
- & - & 3 \\
+ & + & 3 \\
Total & + & 151 \\
\hline
\end{tabular}

+ Positive - negative

* The culture result was inconclusive in cervical specimens from 10 patients, in urethral specimens from three patients, and in both specimens from four patients. In one patient the urethral culture was spoiled by bacterial overgrowth but the cervical specimen yielded chlamydia.

\section{Group 3}

C trachomatis was not isolated in samples from any of the infants of the first 108 puerperal mothers studied when examined at six or seven days after birth. Nine of their mothers harboured chlamydia in the cervix. The infants of these nine mothers were reexamined between 10 and $\mathbf{3 0}$ days after birth as were a further 14 infants of the remaining 185 mothers who were infected with $C$ trachomatis. At this time five infants harboured chlamydia in their conjunctival folds, four of whom were not found to be infected when examined at six or seven days after birth (Table III).

\section{SEROLOGICAL STUDIES}

The reciprocal titres of IgG antichlamydial antibodies in the 139 cord blood samples studied are shown in Table IV. Antibodies at a titre of $1 / 32$ or greater were found in $25 \%$ of the specimens tested.

TABLE III Chlamydial isolation results from conjunctival folds of neonates at different ages

\begin{tabular}{llll}
\hline $\begin{array}{l}\text { Age } \\
\text { (days) }\end{array}$ & No of infants & $\begin{array}{l}\text { No of mothers } \\
\text { with positive cervical } \\
\text { results for chlamydia }\end{array}$ \\
\cline { 2 - 4 } & Examined & Infected & 9 \\
$6-7$ & 108 & 0 & 93 \\
$10-30$ & 23 & 5 & 23 \\
\hline
\end{tabular}

TABLE IV IgG antichlamydial antibodies in cord blood from 139 neonates tested by a micro-immunofluorescence test

\begin{tabular}{llllllllll}
\hline & \multicolumn{1}{c}{ Antichlamydial antibody } & (reciprocal of titre) \\
\cline { 2 - 9 } & $\leqslant 16$ & 32 & 64 & 128 & 256 & 512 & 1024 & 2048 \\
\hline $\begin{array}{l}\text { No of } \\
\text { neonates }\end{array}$ & 104 & 15 & 11 & 3 & 2 & 2 & 1 & 1 \\
\hline
\end{tabular}

\section{Discussion}

In this study $C$ trachomatis was recovered from $6 \cdot 1 \%$ of the pregnant (women applying for legal abortion during the first trimester) and from $8 \cdot 4 \%$ of the puerperal women studied. All these women were inhabitants of the cities of Helsingborg and Landskrona or of the surrounding rural areas (a total of approximately 200000 inhabitants). These cities are located by the strait of Öresund in a mixed industrial and agricultural area with close contacts with the metropolitan region of Copenhagen. Both groups of women studied comprised consecutive cases treated at the gynaecological departments in these two cities. In Landskrona, which has 51000 inhabitants, about 400 children are born annually, and during recent years about 600 women have applied annually for legal abortion in the Helsingborg-Landskrona region.

The chlamydial isolation rate in the women in the present study is similar to that reported in pregnant women in the United States $(5-13 \%) .{ }^{1}{ }^{13}$ These figures are somewhat higher than those for healthy, non-pregnant women who have served as controls in studies of women attending venereal disease clinics; the incidence has usually been less than $5 \% .^{120}$ Moreover, we have isolated the organism in $10-30 \%$ of women attending venereal disease and gynaecological clinics in the same county (Skåne) as the women in the present study (Mårdh et al, unpublished data).

As shown by the present study, the age distribution of the individuals studied influences the isolation rate of $C$ trachomatis. In our series of sexually active persons the younger the women the more frequently the organism was isolated. This was also true in an earlier study of patients attending a gynaecological clinic in the same hospital catchment region ${ }^{21}$ and in a recent study of pregnant women in the United States. ${ }^{13}$ The comparatively low prevalence of genital chlamydial infection in the older age groups suggests that such infections are often self-limiting or that these women are less sexually active.

In non-pregnant, non-puerperal women with clinical signs of infection of the lower genital tract $C$ trachomatis may be found significantly more often 
than in those without such signs. ${ }^{6}$ However, whether or not a pregnant or puerperal women harbours chlamydia is extremely difficult to establish merely by clinical examination alone. The high incidence of asymptomatic female carriers of $C$ trachomatis ${ }^{45}$ indicates that the cervix is an important reservoir for the spread of the organism in the community, as is shown in the present study. None of the chlamydiapositive puerperal women had complained of symptoms suggesting genital infection; this was also true of most of the women who had applied for abortion and who harboured $C$ trachomatis.

It has been claimed that $C$ trachomatis is a more common cause of sexually transmitted disease than is $N$ gonorrhoeae. This claim is supported by the findings in the present study.

A comparison of the results of the cervical and urethral cultures in the puerperal women showed that $C$ trachomatis could be recovered most often from cervical specimens. The cervix must therefore be recommended as the sampling site if lack of laboratory facilities restricts the number of specimens that can be investigated. However, a urethral specimen should also be taken if possible from puerperal women, as $C$ trachomatis was isolated from the urethra alone in three $(17 \%)$ of 18 culture-positive women.

The micro-IF test detects species-specific antibodies to $C$ trachomatis. ${ }^{22}$ Since IgG antibodies pass through the placental barrier it should be possible to study their production in the mother by examining samples of cord blood. The result of our serological study indicated that at least one-third-or 5-6 times as many women as shown by the culture studies-had been exposed to $C$ trachomatis. In principle, similar findings have been reported by others. ${ }^{23}$

The risk of a newborn baby acquiring an eye infection due to $C$ trachomatis, when the mother is harbouring the organism in the cervix, has been estimated to be between 23 and $60 \% . .^{813} 24-26$ In our study, only $22 \%$ of the babies of chlamydia-positive mothers harboured chlamydia in their conjunctival folds. Frommel et $a l^{13}$ in a study of neonates, reported that nasopharyngeal specimens gave a positive result for chlamydia more frequently than specimens from the eyes. In the present study conjuctival specimens were collected from five of the 23 infants of chlamydia-positive mothers, but all gave a negative result.

The results of our study indicate that the time of sampling influences the isolation rate of chlamydia from the eyes of neonates. Four children in our study were chlamydia-negative at six to seven days after birth but harboured chlamydia in their conjunctival folds when re-examined three to 23 days later. From other studies, ${ }^{927}$ the incubation period of ophthalmia neonatorum caused by chlamydia can be as short as a few days. All the infants in our study had been treated prophylactically with silver nitrate on the day of delivery. Although it is known that Credé prophylaxis does not inhibit the growth of $C$ trachomatis, ${ }^{25}$ it might have prolonged the incubation period and possibly also modified the clinical course.

None of the neonates harbouring chlamydia in their eyes showed such signs of infection as discharge, reddening, bulging, or oedema. This is in contrast to Rees and his co-workers, ${ }^{9}$ who found clinical signs of infection in all of 33 infants infected with chlamydia in their eyes. Because the infection was detected early and treatment was begun as soon as the result of the cultures was known, signs of conjunctivitis may have been prevented from developing.

An increasing number of reports from North America $^{14} 152528$ and from Europe ${ }^{29}$ have shown that C trachomatis may cause pneumonia in neonates. This type of neonatal pneumonia, which may occur with or without signs of conjunctivitis, was not diagnosed in any of our children.

Martin and his co-workers ${ }^{30}$ recently reported that the relative risk of stillbirth or neonatal death after 20 weeks' gestation was significantly increased (approximately ten-fold) among chlamydia-positive women compared with chlamydia-negative controls who were matched for age, race, socioeconomic status, and number of pregnancies. Frommel et $a l,{ }^{13}$ however, did not find any correlation between genital chlamydial infection in pregnant women on one hand and difficulties of labour and delivery, initial condition of the neonate, and postpartum complications on the other.

The incidence of post-abortion and puerperal complications of primary genital chlamydial infections could not be established in the present study, as all carriers of $C$ trachomatis, as well as their sexual consorts, were treated with doxycycline. In venereal disease clinic patients, this treatment is known to eradicate $C$ trachomatis effectively. However, in another study (Møller $e t$ al, unpublished observations) of women who underwent legal abortion and who received no antibiotic treatment, we found retrospectively that acute salpingitis had developed in several patients whose cervical specimens collected before abortion had yielded chlamydia. In some of these patients, we have evidence that the salpingitis was caused by $C$ trachomatis. Thus, the diagnosis of genital chlamydial infection in women in whom abortion is performed and treatment with antibiotics if the women are chlamydia-positive are clearly important. 
The high incidence of genital chlamydial infection in pregnant women suggests that steps should be taken routinely to detect such infections, particularly in young women. At present, however, limited laboratory resources make this difficult. Further studies are also needed before any recommendations can be made as to whether or not antibiotic treatment should be given to all pregnant women who are found to be carriers of $C$ trachomatis.

The infants harbouring chlamydia in their eyes were treated with oral erythromycin and chloromycetin ointment to prevent bacterial secondary infections as soon as the culture results were known. No control cultures were performed, but none of the infants developed signs of conjunctivitis or pneumonia during the follow-up period of three to 18 months. Although chlamydial conjuctivitis and pneumonia seem generally to be self-limiting the risk that the infant might develop severe eye infection, or even sequelae, seems to justify general treatment with erythromycin in infants in whom $C$ trachomatis has been recovered. Viral pneumonia during infancy holds a high risk of respiratory-tract complications during later life; ${ }^{31}{ }^{32}$ whether or not this is also true of pneumonia caused by $C$ trachomatis is not known. Antibiotic treatment may also prevent the transmission of chlamydia to other members of the family. ${ }^{33}$

This study was supported by grant $16 \mathrm{X}-4509$ from the Swedish Medical Research Council.

\section{References}

1. Schachter J. Chlamydial infections. N Engl J Med 1978; 298: 428-35; 490-5; 540-9.

2. Mårdh P-A, Ripa T, Svensson L, Weström L. Chlamydia trachomatis infection in patients with acute salpingitis. NEngl J Med 1977; 296: 1377-9.

3. Berger RE, Alexander ER, Harnisch JP, Paulsen CA, Mondo GD, Ansell J, Holmes KK. Etiology, manifestations and therapy of acute epididymitis: Prospective studies of 50 cases. $J$ Urol 1979; 121: 750-4.

4. MacD Burns DC, Darougar S, Thin RN, Lothian L, Nicol CS. Isolation of Chlamydia from women attending a clinic for sexually transmitted diseases. Br J Vener Dis 1975; 51: 314-8.

5. Nayyar KC, O'Neill JJ, Hambling MH, Waugh MA. Isolation of Chlamydia trachomatis from women attending a clinic for sexually transmitted diseases. $\mathrm{Br} J$ Vener Dis 1976; 52: 396-8.

6. Paavonen J, Saikku P, Vesterinen E, Meyer B, Vartiainen E, Saksela $E$. Genital chlamydial infections in patients attending a gynecological outpatient clinic. Br J Vener Dis 1978; 54: 257-61.

7. Schachter J, Dawson CR. Is trachoma an ocular component of a more generalized chlamydial infection? Lancet 1979; 1: 702-3.

8. Chandler JW, Alexander ER, Pheifer TA, Wang S-P, Holmes KK, English M. Ophthalmia neonatorum associated with maternal chlamydial infections. Trans Am Acad Ophthalmol Otolaryngol 1977; 83: 302-8.

9. Rees E, Tait IA, Hobson D, Byng RE, Johnson FWA. Noenatal conjunctivitis caused by Neisseria gonorrhoeae and Chlamydia trachomatis. Br J Vener Dis 1977; 55: 173-9.
10. Jones BR. Prevention of blindness from trachoma. Trans Ophthalmol Soc UK 1975; 95: 16-33.

11. Watson PG, Gairdner D. TRIC agent as a cause of neonatal eye sepsis. Br Med J 1968; 3: 527-8.

12. Nordhorst $\mathrm{CH}$, Dawson C. Sequalae of neonatal inclusion conjunctivitis and associated disease in parents. $\mathrm{Am}$ Ophthalmol 1971; 71: 861-7.

13. Frommel GT, Rothenberg R, Wang S-P, et al. Chlamydial infection of mothers and their infants. J Pediatr 1979; 95: 28-32.

14. Beem MO, Saxon EM. Respiratory tract colonization and a distinctive pneumonia syndrome in infants infected with Chlamydia trachomatis. N Engl J Med 1977; 293: 306-10.

15. Tipple MA, Beem MO, Saxon EM. (1979). Clinical characteristics of the afebrile pneumonia associated with Chlamydia trachomatis infection in infants less than 6 months of age. $J$ Pediatr 1979; 63: 192-7.

16. Gordon FB, Harper IA, Quan AL, Treharne JD, Dwyer RSt C, Garland JA. Detection of Chlamydia (Bedsonia) in certain infections of man. I Laboratory procedures, comparison of yolk sac and cell culture detection and isolation. $J$ Infect Dis 1969; 120: 451-62.

17. Ripa KT, Mårdh P-A. Cultivation of Chlamydia trachomatis in cycloheximide-treated McCoy cells. J Clin Microbiol 1977; 6: 328-31.

18. Mårdh P-A, Mårtensson D, Soltesz LV. A new effective culture medium for Neisseria gonorrhoeae. Sex Transm Dis 1978; 5: 10-3.

19. Treharne JD, Darougar S, Simmons PD, Thin RN. Rapid diagnosis of chlamydial infection of the cervix. Br J Vener Dis 1978; 54: 403-8.

20. Hilton AL, Richmond SJ, Milne JD, Hindley F, Clarke SKR Chlamydia $A$ in the female genital tract. Br J Vener Dis 1974; 50: $1-10$.

21. Ripa KT, Svensson L, Mårdh P-A, Weström L. Chlamydia trachomatis cervicitis in gynecologic outpatients. Obstet Gynecol 1978; 52: 698-702.

22. Wang S-P, Graystone JT. Human serology in Chlamydia trachomatis infection with microimmunofluorescence. $J$ Infec Dis 1974; 130: 388-97.

23. Treharne JD, Darougar S, Jones BR. Modification of the microimmunofluorescence test to provide a routine serodiagnostic test for chlamydial infection. J Clin Pathol 1977; 30: $510-7$.

24. Alexander ER, Chandler J, Pheifer TA, Wang S-P, English M, Holmes KK. Prospective study of perinatal Chlamydia trachomatis infection. In: Hobson $\mathrm{D}$, Holmes $\mathrm{K}$, eds. Nongonococcal Urethritis and Related Infections. Washington DC: American Society for Microbiology, 1977: 148-52.

25. Schachter J, Dawson CR. Inclusion conjunctivitis of the newborn and chlamydial pneumonia in infants. In: Schachter JS, Dawson CR, eds. Human Chlamydial Infections. Littleton: PSG Publishing Company, 1978: 111-20.

26. Lumicao GG, Gyves MT, Stuart LA, Heggie AD. Prospective study of perinacal infections with Chlamydia trachomatis. Pediatr Res 1979; 13: 464

27. Freedman A, Al-Hussaini MK, Dunlop EMC, et al. Infection by TRIC agent and other members of the Bedsonia group: with a note on Rieter's disease. Trans Ophthalmol Soc UK 1966; 86: 313-20.

28. Beem MO, Saxon E, Tipple MA. Treatment of chlamydial pneumonia of infancy. J Pediatr 1979; 63: 198-203.

29. Hallberg A, Mårdh P-A, Persson K, Ripa T. Pneumonia associated with Chlamydia trachomatis infection in an infant. Acta Paediatr Scand 1979; 68: 765-7.

30. Martin DH, Alexander ER, Eschenbach et al Prospective study of chlamydia infection in pregnancy. Abstract C3. In: Proceedings of Sexually Transmitted Diseases, 2nd meeting, Helsinki, Finland, 9-10 August 1979.

31. Rooney JC, Williams HE. The relationship between proven viral bronchiolitis and subsequent wheezing. J Pediatr 1971; 79: 744-7.

32. Burrows B, Knudson RJ, Lebowitz MD. The relationship of childhood respiratory illness to adult obstructive airway disease. Am Rev Respir Dis 1977; 115: 751-60.

33. Jones BR. Ocular syndromes of TRIC virus infection and their possible genital significance. $B r J$ Vener Dis $1964 ; 40:^{`} 3-18$. 